\title{
A Literature Review of Total Hip Arthroplasty in Patients with Ankylosing Spondylitis: Perioperative Considerations and Outcome
}

\author{
S.E. Putnis ${ }^{*}, 1$, G.K. Wartemberg ${ }^{1}$, W.S. Khan ${ }^{2}$ and S. Agarwal ${ }^{3}$ \\ ${ }^{1}$ Joint Reconstruction Unit, Royal National Orthopaedic Hospital, Stanmore, Middlesex, HA7 4LP, UK \\ ${ }^{2}$ University College London Institute of Orthopaedics and Musculoskeletal Sciences, Royal National Orthopaedic \\ Hospital, Stanmore, Middlesex, HA7 4LP, UK \\ ${ }^{3}$ Cardiff \& Vale Orthopaedic Centre, Llandough University Hospital, Cardiff \& Vale NHS Trust, Cardiff, CF5 2LD, UK
}

\begin{abstract}
Ankylosing spondylitis is a spondyloarthropathy affecting the sacro-iliac joints with subsequent progression to the spine and the hip joints. The hip joints are affected by synovitis, enthesial inflammation, involvement of medullary bone, progressive degeneration and secondary osteoarthritis. Clinical presentation is usually in the form of pain and stiffness progressing to disabling fixed flexion contractures and in some instances, complete ankylosis. Hip arthroplasty should be considered for hip pain, postural and functional disability, or pain in adjacent joints due to hip stiffness. We conducted a literature review to determine peri-operative considerations and outcome in ankylosing spondylitis patients undergoing hip arthroplasty. In this review, we have discussed pre-operative surgical planning, thromboprophylaxis, anaesthetic considerations and heterotopic ossification. Outcomes of arthroplasty include range of movement, pain relief, survivorship and complications.
\end{abstract}

Keywords: Ankylosing spondylitis, arthroplasty, complications, hip, literature review, outcome, peri-operative considerations.

\section{INTRODUCTION}

Ankylosing spondylitis (AS) is a seronegative inflammatory rheumatologic disease of unknown etiology characterised by inflammation of joints of the axial skeleton. It is one of a number of Human Leucocyte Antigen (HLA) B27 associated inflammatory disorders which are classified under the umbrella terminology of Spondyloarthritis.

The disease often affects the sacro-iliac joints initially, with subsequent progression to the spine and the hip joints. Tendon attachments around affected joints become inflamed predisposing them to develop fibrosis, followed by calcification and finally resulting in joint ankylosis. The extent of skeletal involvement can vary widely. However, with the potential for complete ankylosis of the axial skeleton and involvement of the hips, the resultant deformities can lead to severe functional impairment. Hip arthroplasty is offered when hip pain becomes severe or when restricted movements adversely affect function.

AS typically affected patients in the second to forth decades of their lives, with a male to female ratio of $3: 1$. A recent systematic literature research demonstrated the variation in prevalence of AS between continents and reported the mean per 10,000 (from 36 eligible studies) as 23.8 in Europe, 16.7 in Asia, 31.9 in North America, 10.2 in Latin America and 7.4 in Africa [1].

*Address correspondence to this author at the Joint Reconstruction Unit, Royal National Orthopaedic Hospital, Stanmore, Middlesex, HA7 4LP, UK;

Tel: +44 (0) 7900 248583; Fax: +44 (0) 208954 2301;

E-mail: svenputnis@doctors.org.uk

\section{INDICATIONS FOR HIP ARTHROPLASTY}

The reported prevalence of hip disease in AS varies from between 19 and $36 \%$ [2, 3], with $90 \%$ presenting with bilateral symptoms [4]. The hip joint can be affected by a number of processes including synovitis [5], enthesial inflammation [6], involvement of medullary bone [7], progressive degeneration and secondary osteoarthritis. Clinical presentation is usually in the form of pain and stiffness progressing to disabling fixed flexion contractures and, in some instances, complete ankylosis. There are postural and functional challenges consequent to this. In general, a hip with bony ankylosis is painless and, if in a functional position, may provide a stable platform for ambulation [8,9]. However, mobilising with a fused hip requires adequate spinal mobility and normal functionality on the contralateral side. This often lacks in patients with AS.

Hip arthroplasty could be considered for hip pain, or postural and functional disability. Another indication is pain in adjacent joints due to stiffness in the hip [10].

One study placed the risk of requiring a total hip replacement within 30 years of a diagnosis of AS between 12 and $25 \%$ [2]. A number of risk factors have been identified for those patients who are more likely to require hip arthroplasty. Patients with Juvenile-onset AS present both clinically and radiologically with more peripheral joint involvement requiring arthroplasty [11]. A restriction of axial mobility [12] and limited flexion and extension of the hip joint [13] have also been identified as risk factors.

A review of AS patients in the Norwegian Arthroplasty Register (which has covered $98 \%$ of primary hip 
arthroplasties in Norway since 1988) showed the mean age at surgery increased significantly from 49.9 years prior to 2002 and 56.4 years thereafter, which led to a suggestion that this may be related to the introduction of TNF-alpha inhibitors [14].

We conducted a literature review to determine perioperative considerations and outcome in AS patients undergoing hip arthroplasty. Table 1 summarises the outcomes of total hip arthroplasty in these patients reported in the English literature and includes the number of hips operated on, the implant type, mean follow-up, postoperative range of movement, pain relief, incidence of heterotopic ossification, survivorship and revisions.

\section{PERI-OPERATIVE CONSIDERATIONS}

\section{Pre-Operative Planning}

AS patients present with debilitating pain and postural deformity through a combination of spinal, pelvic and hip disease. This poses unique problems for hip arthroplasty surgeons. Careful clinical and radiographic assessment of the entire spine, pelvis and lower limbs is essential to accurately evaluate the effect that surgery will have on function. Standing antero-posterior and lateral long leg films are recommended to assess postural alignment [15].

Surgical management of deformity primarily involves hip arthroplasty and, less frequently, spinal osteotomy for correction of kyphotic deformity [16]. Occasionally a patient may require both. Earlier papers suggested that hip arthroplasty should be performed first [17-19]. A review of 28 consecutive patients who underwent both a spinal osteotomy and a total hip arthroplasty (22 spine osteotomy first, 6 arthroplasty first), revealed two anterior dislocations in the group having hip arthroplasty prior to spinal correction, leading the authors to recommend spinal correction prior to embarking on hip arthroplasty [20]. Tang et al. [15] also reported two anterior dislocations in a series of 58 hips using the posterior approach. They went on to recommended spinal surgery first in cases of severe spinal kyphosis.

Preventing hip dislocation is an important pre-operative and intra-operative consideration. The functional position of the arthroplasty, taking into account of any alterations, future spinal surgery will produce, is paramount. Patients often present with posterior pelvic tilt are as part of their axial disease or to compensate for fixed hip flexion. The higher rate of anterior dislocations has been blamed on this, with subsequent recommendations to insert the cup with less anteversion [15]. Debarge et al. reported that the pelvis of patients with ankylosing spondylitis tilted posteriorly by a mean of $15^{\circ}$ compared to normal subjects [21]. A parametric experimental model to evaluate posterior pelvic tilt and arthroplasty instability found that $20^{\circ}$ of posterior pelvic tilt failed to achieve a safe range of movement, when the cup was positioned in the Lewinnek's safe zone. Reduced anteversion in the range of $0^{\circ}$ to $10^{\circ}$ appeared to be acceptable to compensate for pelvic tilt [22].
Additional contracture releases for AS patients are common, and again, these need to be considered both preoperatively and intra-operatively. Knee contractures may be accentuated by hip surgery and may need to be addressed separately [23]. Fixed flexion deformity of the hip may require sequential intra-operative release of the anterior capsule, adductor longus tendon and iliopsoas.

\section{Anaesthetic Considerations}

Ankylosing Spondylitis can have a number of extraarticular manifestations. Cardiac manifestations have been termed as HLA-B27 Cardiac Syndrome consisting of aortic insufficiency, conduction disturbances of the atrioventricular node with a probable subsequent indication for a paced rhythm, and myocardial involvement with a possible compromise of left ventricular function [24]. Involvement of the chest wall leads to reduced chest expansion with compromise of pulmonary function and this should be assessed preoperatively. Intubation can be complicated by cricoarytenoid arthritis, vocal cord fixation and deformities of the temporomandibular joints and cervical spine. A combination of cervical kyphosis and osteoporosis also leads to complexities in patient positioning. A rigid, unsupported, cervical spine is most susceptible to hyperextension injuries, and this is the most common site for fractures in AS patients [25]. Reports in the literature of a fracture dislocation of the lumbar vertebrae during the peri-operative period [26] and two cases of iatrogenic paraplegia after thoracic extension fractures when undergoing hip arthroplasty serve as stark reminders of the difficulties in transferring and positioning AS patients [27].

\section{Thromboprophylaxis}

With no current worldwide consensus on thromboprophylaxis for hip arthroplasty and studies refuting national guidelines [28], centres may currently have individual local guidelines. There is no evidence to suggest AS patients have a different risk to other hip arthroplasty patients. A study in China with a cohort of predominantly young and thin AS patients found a decreased rate of deep vein thrombosis when comparing 54 arthroplasties in the AS group with 95 arthroplasties in an osteoarthritic group [29].

\section{Heterotopic Ossification}

Heterotopic ossification ( $\mathrm{HO})$ is a complication that can impact patients with AS undergoing hip arthroplasty. Early studies reported high rates of between $9 \%$ and $100 \%[18,19$, 30-34]. Brinker et al. went as far as critically reviewing these papers and revealing potential confounding risk factors such as the use of a trochanteric osteotomy or pre-operative bony ankylosis. Additional risk factors have also been identified; patients who have had multiple operations on the hip or those that develop post-operative infection [36].

Not all patients with radiographic signs of $\mathrm{HO}$ will develop symptoms. Brooker's [37] scale of I-IV quantifies the extent and therefore severity of $\mathrm{HO}$, ranging from small 
Table 1. Summary of outcomes following total hip arthroplasty in ankylosing spondylitis reported in the english literature.

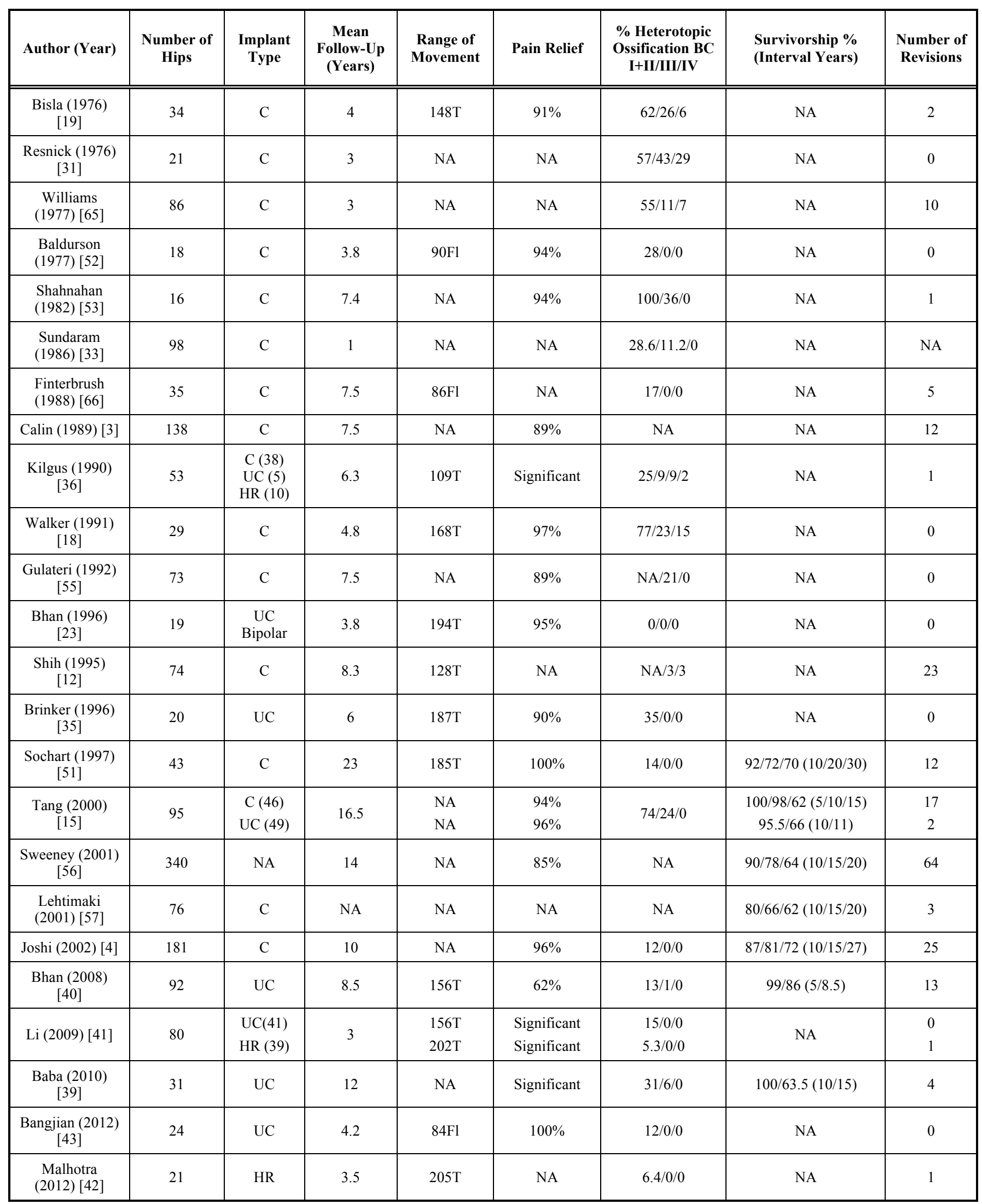


islands of ossification to apparent ankylosis. HO can be commonly seen in hip arthroplasty in general, with one series reporting a rate as high as $47 \%$; despite this only $11 \%$ had clinical symptoms and these were all graded Brooker 3 or 4 [38]. The HO rate analysis seen in Table $\mathbf{1}$ is therefore divided into three groups Brooker I and II, Brooker III, and Brooker IV to reflect the likely functional outcomes. Only one in the five most recent studies in the analysis revealed any clinically significant $\mathrm{HO} ; 6$ out of 31 hips with Brooker Grade 3 [39]. No prophylaxis was used in this study, whilst three out of the remaining four studies used prophylactic Indomethacin [40-42] and one other paper did not [43].

Prophylaxis of HO has largely been with the use of nonsteroidal anti-inflammatory drugs (NSAIDs) and perioperative radiation therapy. NSAIDs reduce $\mathrm{HO}$ by inhibiting inflammatory cells that aid in remodelling and formation of bone [44, 45]. Post-operative treatment should start within 5 days. The duration of therapy has ranged from 7 days to 6 weeks in different studies with comparable outcomes [44]. There was no significant difference found between the different types of NSAIDs; Indomethacin, diclofenac or naproxen [46]. The risks of NSAIDs, gastric ulceration, renal impairment and cardiovascular complications, need to be considered, and intra-operative fracture healing could also be affected. Additionally, integration of cementless components may be negatively influenced by use of NSAIDs. Radiation therapy has been used to prevent and treat $\mathrm{HO}$, by virtue of its potential to target pleuripotential mesenchymal cells, thereby reducing or halting formation of new bone. Hashem et al. recruited 47 patients at high risk of $\mathrm{HO}$, including patients with $\mathrm{AS}$, and treated all of them with post-arthroplasty radiotherapy. They showed statistically low rates of HO [47]. In a larger study of eighty-six hips treated with pre-operative radiation as prophylaxis against $\mathrm{HO}$, utilising varying doses of radiation, the rate of $\mathrm{HO}$ was low suggesting that this was an effective measure. The rates did not differ with increasing dose of radiation. Complications highlighted from this study included non-union in cases of trochanteric osteotomy and trochanteric bursitis [48]. In general NSAIDs seem to provide superior results when compared to radiation with the added benefit of analgesia [46].

In conclusion there is no strong evidence that all AS patients undergoing total hip arthroplasty should receive $\mathrm{HO}$ prophylaxis. However in patients with a history of $\mathrm{HO}$, multiple surgery, or infection, prophylaxis should be considered in the form of pre-operative and post-operative radiation and NSAIDs.

\section{OUTCOMES}

In 1970 Welch and Charnley [49] published results on low friction arthroplasty of the hip in Rheumatoid Arthritis and AS. 307 hips were included of which 33 were in AS patients. Outcomes were presented in a combined group with $94.7 \%$ of patients reporting absolute pain relief and 3.9\% temporary intermittent discomfort. An overall increase in mobility was also reported. Since these early reports a relatively large number of retrospective series have been published. These papers reveal the evolution from using entirely cemented prostheses to more recent series of patients where uncemented prostheses were used. AS patients are on average a young group to require hip arthroplasty and there is now increasing evidence of prolonged survivorship in these groups when uncemented prostheses are used [50]. There are two series using metal resurfacing arthroplasties which have additionally been included in the review of outcomes (Table 1).

The variation in the type of prosthesis used and the lack of a universal pre-operative grading system to evaluate the severity of pre-operative hip disease makes comparisons difficult and must be reviewed with this consideration.

\section{Range of Motion}

When range of motion was accurately measured, they have universally been good. Post-operative range has improved as would be expected. The mean average across the ten papers that reported a total combined mean postoperative range of motion, was 167 degrees [12, 18, 19, 23, $35,36,40-42,51]$. The highest range of post-operative motion was seen in the hip resurfacing groups (202 and 205 degrees) [41, 42].

\section{Pain Relief}

A number of papers have reported significant relief of pain, and others have quantified this with a percentage of post-operative patients who are pain free or very occasionally experience mild pain. Grouping this together revealed the average percentage of excellent pain relief across these 14 papers as $91.6 \%[3,4,15,18,19,23,35,40$, $43,51-55]$. This figure is lowered by the results of Bhan et al. [40] who only included patients with pre-operative bony ankylosis and subsequently reported a rate of $62 \%$. They also went on to comment that in this specific group of patients, some were painfree preoperatively and subsequently developed pain after hip arthroplasty.

\section{Survivorship}

Seven of the studies analysed in this review provided Kaplan Meyer analysis of survivorship over time, and six had at least 15 years follow-up. Across these papers the calculated mean survival at 10 years was $91.8 \%$ and at 15 years $71.75 \%[4,15,39,51,55,56]$. Prior to this analysis Calin and Elswood reported 12 revisions in 138 hips over a follow-up period of 1-34 years [3]. These results are encouraging and can be quoted as part of the decision process for the AS patient deciding on hip arthroplasty.

When revision surgery not for infection has been required (aseptic loosening), it is more frequently due to acetabular component loosening rather than femoral stem loosening.

\section{Complications}

With a patient group containing a high number of fixed deformities, ankylosis, abnormal posterior pelvic tilting, inflexible spines and osteoporosis it is in not surprising that there are a number of reported complications. Both anterior and posterior dislocations have been reported with a far higher number of anterior dislocations when compared to routine hip arthroplasty from a posterior approach for osteoarthritis $[15,21,40]$. Fractures are not only seen in the 
spine due to transfer and positioning of patients $[11,12]$, but intra-operatively around the proximal femur which can be osteoporotic and difficult to access without adequate soft tissue releases [18, 35, 38, 39, 42, 48].

\section{DISCUSSION}

Hip involvement is more common in juvenile or generally earlier onset AS, and is often seen bilaterally. The survivorship of the resultant arthroplasties therefore becomes paramount in both patient's and clinician's minds. It is therefore useful to discuss and compare the outcome of AS hip arthroplasty with groups of young patients who required hip arthroplasty for other reasons. A recent systematic review of total hip arthroplasty in patients under 30 years old with a variety of causative pathologies for their severe hip disease (predominantly osteonecrosis, juvenile rheumatoid arthritis and developmental dysplasia) found substantial clinical improvements in patients' function and pain. The revision rate across all papers was $19.86 \%$ for the acetabular components and $6.5 \%$ for the femoral side over a follow up period which ranged from 7.7-20 years [57]. This is comparable with the clinical outcome and revision rate for AS patients and also demonstrates a higher acetabular component failure rate than femoral component failure rate. Of the eight papers systematically reviewed there was a similar mix of cemented and uncemented prostheses and differing bearing surfaces. Further analysis revealed that uncemented hard on hard bearing implants may have a lower revision rate, although more studies with longer follow up are required.

Uncemented stem designs have shown good survivorship at 10 years across all ages $[58,59]$ and in patients under fifty years of age $[59,60]$. Whilst the trend in younger patients is towards uncemented fixation, it is worth noting that the all cemented designs in the earlier papers did not reveal high revision rates, and hence the bearing surface may be a more important factor than the type of bone implant fixation. Polyethylene wear has been shown to be a causative factor for the loosening of acetabular components in situations where the femoral stem has remained well fixed [61]. Hip arthroplasty in young active patients where polyethylene is used provides an environment for wear and subsequent osteolysis [62].

There is no doubt that total hip arthroplasty provides significant pain relief and/or greatly improved range of movement in patients with ankylosing spondylitis [63, 64]. In those that have hip joint ankylosis the procedure is performed to provide functional improvement as hip pain can be minimal. These patients are technically more challenging and may have a higher complication rate or develop new pain, and as such if arthroplasty is likely it should be offered before hip ankylosis. Early results would suggest that a hard on hard bearing could improve the survivorship of the prosthesis, and with the ongoing alerts regarding metal on metal bearings this increasingly points towards the use of ceramic bearings for AS patients [65-68].

\section{CONFLICT OF INTEREST}

The authors confirm that this article content has no conflict of interest.

\section{ACKNOWLEDGEMENTS}

Declared none.

\section{REFERENCES}

[1] Dean LE, Jones GT, MacDonald AG, Downham C, Sturrock RD, Macfarlane GJ. Global prevalence of ankylosing spondylitis. Rheumatology (Oxford) 2014; 53(4): 650-7.

[2] Vander Cruyssen B, Munoz-Gomariz E, Font P, et al. Hip involvement in ankylosing spondylitis: epidemiology and risk factors associated with hip replacement surgery. Rheumatology (Oxford) 2010; 49: 73-81.

[3] Calin A, Elswood J. The relationship between spinal, pelvic and hip involvement in ankylosing spondylitis: one disease process or several? Br J Rheumatol 1988; 27: 393-5.

[4] Joshi AB, Markovic L, Hardinge K, Murphy JCM. Total hip arthroplasty in ankylosing spondylitis. J Arthop 2002; 17(4): 42733.

[5] Chen WS, Chen CH, Lin KC, et al. Immunohistological features of hip synovitis in ankylosing spondylitis with advanced hip involvement. Scan J Rheumatol 2009; 38: 154-5.

[6] Xu L, Sun Q, Jiang S, et al. Changes in gene expression profiles of the hip joint ligament of patients with ankylosing spondylitis revealed by DNA chip. Clin Rheumatol 2012; 31(10): 1479-91.

[7] Yilmaz MH, Ozbayrak M, Kasapcopur O, et al. Pelvic MRI findings of juvenile onset ankylosing spondylitis. Clin Rheumatol 2010; 29: 1007-13.

[8] Hamadouche M, Kerboull L, Meunier A, Courpied JP, Kerboull M. Total hiparthroplasty for the treatment of ankylosed hips: a five to twenty-one-year follow-up study. J Bone Joint Surg Am 2001; 83A(7): 992-8.

[9] Rittmeister M, Starker M, Zichner L. Hip and knee replacement after longstanding hip arthrodesis. Clin Orthop 2000; (371): 13645 .

[10] Lubahn JD, Evarts CM, Feltner JB. Conversion of ankylosed hips to total hip arthroplasty. Clin Orthop 1980; (153): 146-52.

[11] Jadon DR, Ramanan AV, Sengupta R. Juvenile Versus Adult-onset Ankylosing Spondylitis - Clinical, Radiographic, and Social Outcomes. A Systematic Review. J Rheumatol 2013; 40(11): 1797805.

[12] Shih LY, Chen TH, Lo WH, Yang DJ. Total hip arthroplasty in patients with ankylosing spondylitis: long term follow-up. J Rheumatol 1995; 22(9): 1704-9.

[13] Hamdi W, Zeineb A, Ghannouchi M, Associated risk factors with worse functional prognosis and hip replacement surgery in ankylosing spondylitis. Joint Bone Spine 2012; 79: 94-102.

[14] Nystad TW, Furnes O, Havelin LI, et al. Hip replacement surgery in patients with ankylosing spondylitis 2014; 73: 1194-7.

[15] Tang WM, Chiu KY. Primary Total Hip Arthroplasty in Patients With Ankylosing Spondylitis. J Arthop 2000; 15(1): 52-8.

[16] Kubiak EN, Moskovich R, Errico TJ, Di Cesare PE. Orthopaedic management of ankylosing spondylitis. J Am Acad Orthop Surg 2005; 13: 267-78.

[17] Lee ML. Orthopaedic Problems in ankylosing spondylitis. Rheumatism 1963; 19: 79-82.

[18] Walker LG, Sledge CB. Total hip arthroplasty in ankylosing spondylitis. Clin Orthop Rel Res 1991; 262: 198-204.

[19] Bisla RS, Ranawat CS, Inglis AE. Total hip arthroplasty in patienys with ankylosing spondylitis with involvement of the hip. J Bone Joint Surg Am 1976; 58: 233-8.

[20] Zheng GQ, Zhang YG, Chen JY, Wang Y. Decision making regarding spinal osteotomy and total hip replacement for ankylosing spondylitis. Bone Joint J 2014; 96-B: 360-5.

[21] Debarge R, Demey G, Roussouly P. Radiological analysis of ankylosing spondylitis patients with severe kyphosis before and after pedicle subtraction osteotomy. Eur Spine J 2010; 19(1): 6570.

[22] Sato T, NakashimaY, Matushita A, Fujii M, Iwamoto Y. Effects of posterior tilt on anterior instability in total hip arthroplasty: a parametric experimental modelling evaluation. Clin Biomechanics 2013; $28: 178-81$

[23] Bhan S, Malhotra R. Bipolar hip arthroplasty in ankylosing spondylitis. Arch Orthop Trauma Surg 1996; 115: 94-9. 
[24] Lautermann D, Braun J. Ankylosing spondylitis - Cardiac manifestations. Clin Exp Rheumatol 2002; 20(Suppl 28): S11-5.

[25] Guan M, Wang J, Zhao L, Xiao J, Li Z, Shi Z. Management of hip involvement in ankylosing spondylitis. Clin Rheumatol 2013; 32: 1115-20.

[26] Mahesh BH, Jayaswal A, Bhan S. Fracture dislocation of the spine after total hip arthroplasty in a patient with ankylosing spondylitis with early pseudoarthritis. Spine J 2008; 8: 529-33.

[27] Danish SF, Wilden JA, Schuster J. Iatrogenic paraplegia in 2 morbidly obese patients with ankylosing spondylitis undergoing total hip arthroplasty. J Neurospine 2008; 8: 80-3.

[28] Bishnoi A, Swamy G, Majeed H, Abuzakuk T. Thromboprophylaxis after total hip arthroplasty. J Bone Joint Surg Br 2011; 93BIII: 305 .

[29] Shi D, Xu X, Song K, Xu Z, Dai J, Chen D, Jiang Q. Comparison of venous thromboembolism after total hip arthroplasty between ankylosing spondylitis and osteoarthritis. Biomed Res Int 2014; 2014: 712895.

[30] Wilde AH, Collins HR, Mackenzie AH. Re-ankylosis of the hip joint in ankylosing spondylitis after total hip replacement. Arthritis Rheum 1972; 15: 493.

[31] Resnick D, Dwosh IL, Goergen, et al. Clinical and radiographic "reankylosis" following hip surgery in ankylosing spondylitis. AJR Am J Roentgenol 1976; 126: 1181-8.

[32] Taylor AR, Kamdar BA, Arden GP. Ectopic ossification following total hip arthroplasty. J Bone Joint Surg 1976; 58B: 134

[33] Sundaram NA, Murphy JC. Heterotopic bone formation following total hip arthroplasty in ankylosing spondylitis. Clin Orthop Relat Res 1986; 207: 223-6.

[34] Toni A, Baldini N, Sudanese A, Tigani D, Giunti A. Total hip arthroplasty in patients with ankylosing spondylitis with a more than two year follow-up. Acta Orthop Belg 1987; 53(1): 63-6.

[35] Brinker MR, Rosenberg AG, Kull L, Cox DD. Primary noncemented total hip arthroplasty in patients with ankylosing spondylitis. J Arthroplasty 1996; 11(7): 802-12.

[36] Kilgus DJ, Namba RS, Gorek JE, Cracchiolo A III, Amstutz HC. Total hip replacement for patients who have ankylosing spondylitis. J Bone Joint Surg Am 1990; 72(6): 834-9.

[37] Brooker AF, Bowerman JW, Robinson RA, Riley LH. Ectopic ossification following total hip replacement: incidence and a method of classification. J Bone Joint Surg 1973; 55A: 1629.

[38] Kocic M, Lazovic M, Mitkovic M, Djokic B. Clinical significance of the heterotopic ossification after total hip arthroplasty. Orthopedics 2010; 33(1): 16.

[39] Baba T, Shitoto K, Kaneko K, Inoue H, Nozawa M, Maruyama Y. Total hip arthroplasty in Japanese patients with ankylosing spondylitis. Eur J Orthop Surg Traumatol 2010; 20: 613-8.

[40] Bhan S, Eachempati KK, Malhotra R. Primary Cementless Total Hip Arthroplasty for Bony Ankylosis in Patients with Ankylosing Spondylitis. J Arthoplasty 2008; 23(6): 859-66.

[41] Li J, Xu W, Xu L, Liang Z. Hip resurfacing arthroplasty for ankylosing spondylitis. J Arthoplasty 2009; 24(8): 1285-91.

[42] Malhotra R, Kannan A, Kumar V, Nagaraj C, Marimuthu K, Khatri D. Hip Resurfacing Arthroplasty in Inflammatory Arthritis. J Arthroplasty 2012; 27(1): 15-20.

[43] Bangjian $\mathrm{H}$, Peijian $\mathrm{T}, \mathrm{Ju} \mathrm{T}$. Bilateral synchronous total hip arthroplasty for ankylosed hips. Int Orthop 2012; 36: 697-701.

[44] Schmidt SA, Kjaersgaard-Anderson P, Pedersen NW, Kristenscn SS, Pedersen P, Nielsen JB. The use of indomethacin to prevent the formation of heterotopic. Bone after total hip replacement. A randomized, double blend clinical trial. J Bone Joint Surg Am 1988; 70-A: 834-8.

[45] Nagi ON, Dhillon MS, Batth HS. Heterotopic ossification after total hip arthroplasty: A review of etiopathogenesis, risk factors and treatment modalities. Ind J Orthop 2002; 36(4): 225-33.

[46] Macfarlane B, Ng R, Gamie F. Pharmacological treatment of heterotopic ossification following hip and acetabular surgery. Expert Opin Pharmacother 2008; 9(5): 767-86.
[47] Hasham R, Tanzer M, Rene N, Evans M, Souhami L. Postoperative radiation therapy after hip replacement in high-risk patients for development of heterotopic bone formation. Cancer Radiother 2011; 15(4): 261-4.

[48] Pellegrini VD, Gregoritch SJ. Preoperative irradiation for prevention of heterotopic ossification following total hip arthroplasty. J Bone Joint Surg Am 1996; 78(6): 870-81.

[49] Welch RB, Charnley J. Low-Friction Arthroplasty of the Hip in Rheumatoid Arthritis and Ankylosing Spondylitis. Clin Orthop Rel Res 1970; 72: 22-32.

[50] Gee MJ, Ajuied A, Shah Z, George M, Bankes MJK. Systematic review of total hip arthroplasty in patients under 30 years old. Hip Int 2013; 23(4): 345-51.

[51] Sochart DH, Porter ML. Long-term results of total hip replacement in young patients who had ankylosing spondylitis. J Bone Joint Surg Am 1997; 79(8): 1181-9.

[52] Baldurson H, Brattstrom H, Olsson T. Total hip replacement in ankylosing spondylitis. Acta Orthop Scand 1977; 48: 499-507.

[53] Shahnahan WR Jr, Kaprove RE, Major PA, Hunter T, Baragar FD. Assessment of long term benefit of total hip replacement in patients with ankylosing spondylitis. J Rheumatol 1982; 8: 101-4.

[54] Gualtieri G, Gualtieri I, Hendriks M, Gagliardi S. Comparison of cemented ceramic and metal-polyethylene coupling hip prostheses in ankylosing spondylitis. Clin Orthop Rel Res 1992; 282: 81-5.

[55] Sweeney S, Gupta R, Taylor G, Calin A. Total hip arthroplasty in ankylosing spondylitis: outcome in 340 patients. J Rheumatol 2001; 28(8): 1862-6.

[56] Lehtimäki MY, Lehto MU, Kautiainen H, Lehtinen K, Hämäläinen MM. Charnley total hip arthroplasty in ankylosing spondylitis. Acta Orthop Scand 2001; 72(3): 233-6.

[57] Gee MJ, Ajuied A, Shah Z, George M, Bankes MJK. Systematic review of total hip arthroplasty in patients under 30 years old. Hip Int 2013; 23(4): 345-51

[58] Reikeras O, Gunderson RB. Excellent results of HA coating on grit-blasted stem: 245 patients followed for 8-12 years. Acta Orthop Scand 2003; 74(2): 140-4

[59] Loupasis G, Hyde ID, Morris EW. The furlong hydroxyapatite coated femoral prosthesis: a 4 to 7 years follow up study. Arch Orthop Traum Surg 1998; 117: 132-5.

[60] Capello WN, D’Antonio JA, Feinberg JR, Manley MT. Ten-year results with hydroxyapatite coated total hip femoral components in patients less than fifty years old. A concise follow-up of a previous report. J Bone Joint Surg Am 2003; 85(5): 885-9.

[61] Wangen H, Lereim P, Holm I, Gunderson R, Reikeras O. Hip arthroplasty in patients younger that 30 years: excellent ten to 16 year follow-up results with a HA-coated stem. Int Orthop 2008; 32: 2419-26.

[62] Schmalzried TP, Shepherd EF, Dorey FJ, et al. Wear is a function of use, not time. Clin Orthop Relat Res 2000; (381): 36-46.

[63] Dheerendra S, Khan WS, Saeed MZ, Goddard NJ. Recent developments in total hip replacements: cementation, articulation, minimal-invasion and navigation. J Perioper Pract 2010; 20(4): 133-8.

[64] Minocha A, Khan WS. Hip osteoarthritis: a review on the disease causes, progression and management options for hip osteoarthritis. GM: Midlife Beyond 2015; 45(2): 17-9.

[65] MHRA. Medical Device Alert: All metal-on-metal (MoM0 hip replacements (MDA/2012/008) Issued: 28 February 2012. http: //www.mhra.gov.uk/Publications/Safetywarnings/MedicalDeviceAl erts/CON155761 [Accessed 28/08/2014].

[66] Williams E, Taylor AR, Arden GP, Edwards DH. Arthroplasty of the hip in ankylosing spondylitis. J Bone Joint Surg Br 1977; 59-B: 393-97.

[67] Finterbrush A, Amir D, Vatashki E, Husseini N. Joint surgery in severe ankylosing spondylitis. Acta Orthop Scand 1988; 59: 491-6. Whittingham-Jones P, Khan WS. Advances in ceramic bearings for total hip replacements. Int J Med Biolog Front 2012; 18 (1): 51-5. 